\title{
Experimental Evaluation of a Socially-enhanced Collaborative Learning Tool Based on the Facebook Platform
}

\author{
Félix Fernández-Peña ${ }^{+}$and Pilar Urrutia-Urrutia \\ Universidad Técnica de Ambato
}

\begin{abstract}
Facebook was conceived with a social purpose but, in the last few years, its influence over collaborative learning processes has been broadly studied. However, there is no consensus about its positive or negative impact on the academic performance of students. In this scenario, our intention is to customize social media for collaborative learning through the construction of a Facebook application. This is an original idea since no other studies, found in the area, consider customizing Facebook for the actual coupling of social media with learning tools. This way, we intend to fill in the existing gap between Facebook and collaborative learning in higher education. In this paper, we present the results of a quantitative evaluation of the impact of a socially-enhanced collaborative learning tool on the students' performance. An experiment was carried out during one month. 69 students of Software Engineering participated in the study. The obtained results suggest that the improvement of the students' performance is significant when a custom Facebook application, designed for collaborative learning programs, is used. This findings are statistically supported by a P-value of 2,84x10-4. Nevertheless, a broader study should be carried out in order to elucidate the latent constructs involved in these dynamics.
\end{abstract}

Keywords: Colaborative learning, Facebook, information management system quantitative evaluation.

\section{Introduction}

There is a widespread adoption of social media platforms at college [1-7]. In a study by Junco et al., with 2368 students of a US university, it was determined that the average time using this network is aproximately of 1 hour 40 minutes per day [2]. Students really spend a great deal of psychological energy using, checking, and engaging in a variety of Facebook services [8]. This social media is considered as an increasingly important platform for computer supported collaborative learning [7][9]. Nevertheless, there is no consensus on the usability of Facebook in the learning process [2-3][10].

A literature review shows that the majority of the studies are based on the use of Facebook groups for the academic interaction among students and professors. Collaborative learning spaces are created, making possible the access to information and generating academic discussion, where the student shares his knowledge and gets a feedback of other people's experiences. In the different studies surveys and statistical methods were used, as the main assessment method to evaluate the academic interaction.

Considering the Facebook drawbacks as a tool for supporting the learning process and its possibilities as a platform, this paper proposes to answer the following research question: Is the construction of a custom Facebook application, designed for supporting collaborative learning programs, a way to improve the students' performance? The aim of our work is to define an environment for adapting Facebook to a sociallyenhanced collaborative learning process. The validation of the proposal was based on an experiment that involved students of Software Engineering at the Universidad Técnica de Ambato.

\footnotetext{
+ Corresponding author. Tel.: + 593999235229; fax: +59332851894.

E-mail address: fo.fernandez@uta.edu.ec.
} 
This document is divided as follows. First, related work is analyzed. In section 3, the proposed software tool is described. Next, design and results of the experiment for validating the proposal are discussed. Finally, we arrive to conclusions of the work and propose future work.

\section{Related work}

Some authors have positively evaluated the impact of social media in the empowerment of the argumentative capabilities of students [9] and the capacity for achieving collaborative learning [2][8]. In more recent studies, it has been stated that the use of social media enforces identity, loyalty and trust in educative institutions [11][12] and that making use of a Facebook group improves communication between teachers and students, and students' engagement in the classrooms [7]. This last result apparently contradicts previous research of Junco, who stated that the time spent on Facebook resulted negatively related to engagement [2].

Junco found out that collecting and sharing information in social media was positively predictive of the academic performance [2] but, in a later study, he has concluded that multi-tasking with Facebook is significantly negative predictive of GPA for freshmen, sophomores, and juniors [8].

Çoklar published a positive evaluation of Facebook in the aspects of dissemination of information, arousing interest, motivation and presenting interaction opportunities [13]. In this very study, Çoklar mentions that Facebook faces 1) the inconveniences of been nested with entertainment, 2) the problem of control mechanism and 3) the excessive informational convergence, when used in an academic environment [13]. Much more radically, in Abdulahi's opinion, social network sites have become an "addiction" for students [4].

In Junco's opinion, a higher percentage of those using social network sites (SNSs) participate in and spend more time with peers and in campus organizations, and increased student-teacher interaction take place, compared to those who use SNS less often or not at all [2]. Further, Perez et al. compared Facebook with Content Management Systems (CMSs), concluding that CMSs are less natural for students to discuss with each other about their learning [5].

Students have actually made suggestions about Facebook in terms of its educational usage. They propose 1) to provide teachers with means of supervision, 2) to explote the capabilities of Facebook for collaboration between students and professors and 3) to take into account the quality of the activities carried out in Facebook by students for grading their performance. Coklar published these criteria in a previous study [13].

Divergent opinions in the last couple of years emphasize the interest in using SNSs in academic environments [8][11][12][14]. Nevertheless, until now, Facebook keeps been a non-academic social network and no custom components extending the Facebook's behaviour have seen light for adapting the SNS to the management of a collaborative learning process. Table 1 resumes the purpose of relevant studies of the last three years.

In terms of the kind of the studies carried out, authors like Junco recognize the lack of accuracy of the commonly applied surveys as mechanisms for measuring the impact of social media in education [8]. Tsovaltzi et al. propose the use of specially created Facebook accounts for having access to the actual data in Facebook [9]. In a later study, Nvivo and NCapture were used to download data published on a Facebook Group created on purpose for the experiment [6]. Kitto et al. have constructed an analytics toolkit able to retrieve data of social interactions on social media (not only from Facebook but from Twitter, Diigo and Youtube) [15]. All other revised papers show results based not on quantitative but on qualitative data of Facebook usability in academia. This is a general limitation we try to overcome. 
Table 1: Different studies carried out for determining the usability of Facebook in education

\begin{tabular}{|c|c|c|c|c|}
\hline Source & $\begin{array}{l}\text { Duration of the } \\
\text { experiment }\end{array}$ & $\begin{array}{l}\text { Persons } \\
\text { involved in } \\
\text { the study }\end{array}$ & $\begin{array}{l}\text { Kind of } \\
\text { Study }\end{array}$ & Purpose of the study \\
\hline$[5]$ & 6 months & 24 & $\begin{array}{l}\text { Qualitative } \\
\text { analysis }\end{array}$ & $\begin{array}{l}\text { Pedagogical analysis of the use of FB groups and its impact } \\
\text { on the institutional policies. }\end{array}$ \\
\hline [6] & 1 month & 28 & QCA & $\begin{array}{l}\text { Study of the students behavior in academic activities } \\
\text { through a FB group. }\end{array}$ \\
\hline$[10]$ & Not declared & 112 & $\begin{array}{l}\text { Descriptive } \\
\text { statistics. }\end{array}$ & Study of Facebook's academic use by students. \\
\hline$[15]$ & Not declared & - & - & $\begin{array}{l}\text { Gathering information from social networks using their } \\
\text { APIs. }\end{array}$ \\
\hline$[16]$ & Not declared & 50 & $\begin{array}{l}\text { Descriptive } \\
\text { statistics. }\end{array}$ & $\begin{array}{l}\text { Evaluation of the the students participation in scientific, } \\
\text { academic conferences through a FB group. }\end{array}$ \\
\hline [17] & 6 months & 48 & $\begin{array}{l}\text { Descriptive } \\
\text { statistics. }\end{array}$ & $\begin{array}{l}\text { Analysis of Facebook as a complementary platform to a } \\
\text { traditional LMS. }\end{array}$ \\
\hline$[18]$ & 2 hours & 128 & ANOVA & $\begin{array}{l}\text { Analysis of the contribution of academic discussions } \\
\text { through Facebook to the individual learning process. }\end{array}$ \\
\hline [19] & 12 months & 119 & $\begin{array}{l}\text { Descriptive } \\
\text { statistics. }\end{array}$ & $\begin{array}{l}\text { Analysis of the metacongitive learning development of } \\
\text { students through a FB group. }\end{array}$ \\
\hline$[20]$ & 6 months & 105 & ANOVA & $\begin{array}{l}\text { Analysis of the argumentative learning development of } \\
\text { students through a FB group. }\end{array}$ \\
\hline$[21]$ & 6 months & 71 & $\begin{array}{l}\text { Descriptive } \\
\text { statistics }\end{array}$ & $\begin{array}{l}\text { Study the use of a FB group in the enrichment of a } \\
\text { programming learning program. }\end{array}$ \\
\hline$[22]$ & Not declared & 10 & $\begin{array}{l}\text { Qualitative } \\
\text { analysis }\end{array}$ & Study of the use of Facebook by nursing students. \\
\hline
\end{tabular}

\section{Analysis of the Implemented Software Tool}

A Facebook application (called Sigma) was implemented in order to enhance the collaborative learning process. In this scenario, we understand social interactions as the like, share and visit actions of a Facebook user through any possible way of interaction with the Facebook platform. With an interface similar to the interface of a Facebook group, this application registers social interactions through Facebook in a local database. The main distinction with other proposals is that the application registers necessary data for evaluating the impact of social interactions in a collaborative learning process. Sigma works as an interface between end users and the Facebook platform. Social interactions involving posted educative resources are stored in a local database and reflected on the social network using the Facebook Graph API.

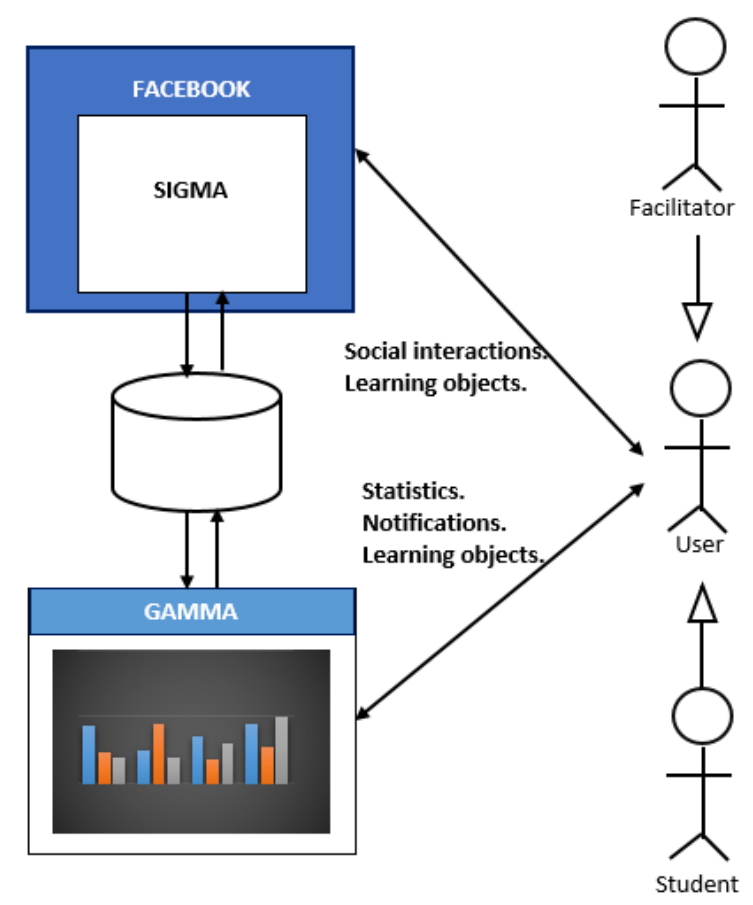

Fig. 1: Software architecture of the socially-enhanced collaborative learning tool. 
The extensibility of the Facebook platform allowed the deployment of the application in the Facebook canvas. Meanwhile, a web application (called Gamma), allow users to post new entries and to query for educative resources without been logged in Facebook. Statistics and email notifications to the users are automatically generated by Gamma. Figure 1 shows the software architecture of the proposal for managing the collaborative learning process.

\subsection{Facebook app Sigma}

Sigma is a web application that lives in the Facebook canvas of users who accept to install it on Facebook. The application is designed for supporting collaboration among students attending to a learning process with the guidance of faculty. Information is shared among all users. Any social interaction of a user is registered in the local database.

Contrary to a Facebook group, Sigma allows to sort information taking into account not only the date of publication but other criteria like relevance and the number of social interactions. For more information about the functionalities of Sigma, there is a demo available at https://www.youtube.com/watch?v=adJ8Q8L17M. This Facebook app allows to publish educative resources in Facebook and determines the level of collaboration of students by quantifying their social interaction in the social media. This way, the proposed software tool takes into account the aforementioned suggestions of students for adapting Facebook to the academic environment.

\subsection{Web application Gamma}

Gamma processes data logged by Sigma, generating reports, notifications and alerts, depending on the user profile and the social interactions taking place at Sigma. Sigma and Gamma share the same database whose design is shown in figure 2. As inferred from the class diagram of figure 2, the learning objects are stored in the table article. These learning objects are classified by a set of categories previously established. Meanwhile, all social interactions with any learning object are registered in the corresponding table (like, share, or visit). Any publication and/or social interaction are associated to the corresponding user.

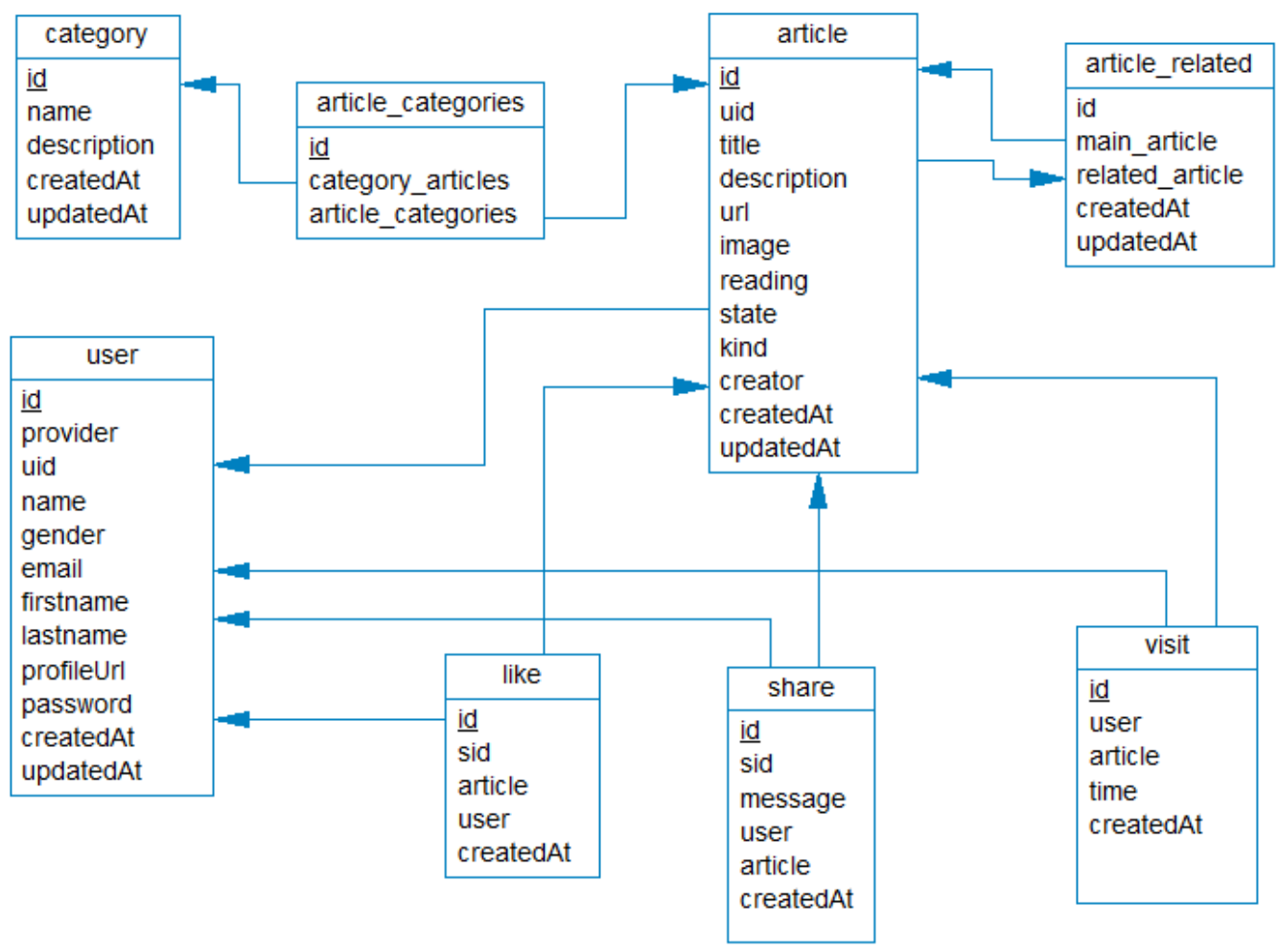

Fig. 2: Database model shared by Sigma and Gamma. 
We may say that Gamma actually closes the management lifecycle of the collaborative learning process by giving feedback to the faculty members about the impact of social interactions. For more information about the functionalities of the application, consult the demo available at https://www.youtube.com/watch?v=yQmaln8Ywt0\&feature=youtu.be.

\section{Experiment Design}

An experiment was designed using randomised block design in order to answer the research question of the study. Students of Software Engineering of the Universidad Técnica de Ambato were called to participate in the study. A total of 69 students were randomly assigned to one of three courses in order to participate in a collaborative course of programming in Java. The hypothesis was set as follows:

Ho: Using the socially-enhanced collaborative learning tool that was built, the performance of the students will improve.

The independent variable in the experiment was set as the mechanism used for collaborative learning. The treatments of the independent variable were: 1) traditional collaborative studying, 2) the use of a Facebook group to collaborate and 3) the use of Sigma and Gamma. The dependent variable of the study was the performance of the students, measured as the grade that students obtained. The domain of the dependent variable was an integer between 1 and 10. The facilitator was always the same and each treatment was applied to one course. The facilitator did not take part of the team who propose the development of the socially-enhanced collaborative learning tool and students gave the researchers permission to access to the grade they obtained in the course.

As an intensive course, Java programming was taught for one month. At the end of the month, we were ready to do an ANOVA test in order to interpret if the differences among the performance of each group were significant. Further, a survey was applied to the students who participated in the experiment in order to determine their feelings about the way that collaborative learning influenced their performance in the course of Java programming.

The survey was based on the one designed by Michikyan et al. [14]. Answer values were set using a Likert scale (values from 1 to 5 , been 1 the less satisfactory and 5 the most satisfactory). The questionnaire included:

- Collaborative learning is useful for learning.

- The course promotes and increases the team work.

- The course promotes the active participation.

- The collaborative environment facilitates the acquisition of knowledge.

- It is easy to share content in the collaborative environment.

\section{Analysis of Results}

The ANOVA test was applied to the grade value that students obtained at the end of the course. We concluded that the difference between the three treatments was significant with a P-Value of 0.000284 , as shown in table 2 . Then, with a post-hoc Tukey test we determined that the difference between traditional collaborative learning and collaborative learning using a Facebook group was not significant. Nevertheless, making use of Sigma and Gamma, the best results of performance in the students were obtained and the difference to both of the other treatments was actually significant.

Table 2: Results of ANOVA analysis of the grade value obtained by students in each treatment

\begin{tabular}{|c|c|c|c|c|c|c|}
\hline $\begin{array}{l}\text { Source of } \\
\text { Variation }\end{array}$ & $S S$ & $d f$ & $M S$ & $F$ & $P$-value & $F$ crit \\
\hline Between Groups & 16,43478 & 2 & 8,217391 & 9,267459 & 0,000284 & 3,135918 \\
\hline Within Groups & 58,52174 & 66 & 0,886693 & & & \\
\hline Total & 74,95652 & 68 & & & & \\
\hline
\end{tabular}


Students involved in the study were between 19 and 21 years old and 16 of them were female (22\% of total sample), $96 \%$ of them were common users of Facebook but only $16 \%$ of them had previous experience using Facebook in any kind of learning process.

The Cronbach' alpha for the results of applying the questionnaire was 0.96 , indicating excellent internal consistency in the responses. The results indicate that students of the three courses considered that collaborative learning was useful for learning. Using PCA, it was determined that, in opinion of the students of all the courses, the facilitator actually promoted team work and active participation the same way, and they had good opinion about it (close to 4.5 in Likert scale). Nevertheless, students of the course where Sigma and Gamma were used were those who considered that it was easier to collaborate and to acquire knowledge.

\section{Conclusions}

Using Sigma, the management of learning objects is actually taking place inside the social media. This is the same that happens with Facebook groups. The main difference between these two alternatives is that with Sigma, the collaboration between users is designed from the point of view of the learning process that takes place. Meanwhile, Gamma allows faculty members to receive an accurate feedback about the social interactions as a consequence of been studying in a collaborative environment. The proposal is original since no other studies in the area were found that consider customizing Facebook as an option for the actual coupling of social media into learning tools.

From our literature review, we found out that using a Facebook group is the most common proposal for using Facebook in learning programs. The result of the current study suggests that the improvement of the students' performance is significant when a custom Facebook application, designed for collaborative learning programs, is used. This result was sustained even when compared to the use of a Facebook Group for supporting collaborative studying, meaning that the results support the hypothesis of the study.

While these findings are statistically strong, more research is necessary to elucidate the latent constructs involved in these dynamics. As future work, a longitudinal study of the influence of the socially-enhanced collaborative learning tool that we built upon the Facebook platform should be carry out.

\section{Acknowledgements}

This research was supported by Universidad Técnica de Ambato, who funds the research project Social Media Academic Network (SOMAN).

\section{References}

[1] P. Kirschner, A. Karpinski, Facebook and academic performance. Computers in Human Behavior. 2010, 26(6): 1237-1245.

[2] R. Junco. Too much face and not enough books: The relationship between multiple indices of Facebook use and academic performance. Computers in Human Behavior. 2012, 28 (1): 187-198.

[3] M. Gómez, S. Roses, P. Farias. The Academic Use of Social Networks among University Students. Comunicar. 2012, 38: $131-138$.

[4] A. Abdulahi, B. Samadi, B. Gharleghi. A Study on the Negative Effects of Social Networking Sites Such as Facebook among Asia Pacific University Scholars in Malaysia. International Journal of Business and Social Science. 2014, 5 (10): 133-145.

[5] J. Pérez, K. Le, J. de la Cruz. Integrating Facebook in the classroom: Pedagogical dilemmas. Journal of Instructional Pedagogies. 2014, 1: 1-10.

[6] C. Chun-Jung, W. Sheng-Yi. A case study exploring junior high school student's interaction behavior in a learning community on Facebook: Day and time. International Journal of Learning, Teaching and Educational Research. 2015, 12 (2): 99-106.

[7] F. Cunha, C. van Kruistum, B. van Oers. Teachers and facebook: using online groups to improve students' 
communication and engagement in education. Communication Teacher. 2016, 30 (4): 228-241.

[8] R. Junco. Student class standing, Facebook use, and academic performance. Journal of Applied Developmental Psychology. 2015, 36: 18-29.

[9] D. Tsovaltzi, A. Weinberger, O. Scheuer, T. Dragon, B. McLaren. Collaborative learning in Facebook: Can argument structure facilitate academic opinion change.? CSCL Conference Proceedings. 2011: 2-5.

[10] L. Donlan. Exploring the views of students on the use of Facebook in university teaching and learning. Journal of Further and Higher Education. 2014, 38 (4): 572-588.

[11] R. Nevzat, Y. Amca, C. Tanova, H. Amca. Role of social media community in strengthening trust and loyalty for a university. Computers in Human Behavior. 2016, 65:550-559.

[12] F. Brech, U. Messer, B. Vander, P. Rauschnabel, B. Ivens. Engaging fans and the community in social media: interaction with institutions of higher education on facebook. Journal of Marketing for Higher Education. 2016: 119.

[13] A. Çoklar. Evaluations of Students on Facebook as an Educational Environment. Turkish Online Journal of Qualtitative Inquiry. 2012, 3(April): 42-53.

[14] M. Michikyan, K. Subrahmanyam, J. Dennis. Facebook use and academic performance among college students: A mixed-methods study with a multi-ethnic sample. Computers in Human Behavior. 2015, 45:265-272.

[15] K. Kitto, S. Cross, Z. Waters, and M. Lupton. Learning Analytics Beyond the LMS: The Connected Learning Analytics Toolkit. Proceedings of the Fifth International Conference on Learning Analytics And Knowledge - LAK '15, ACM. 2015: 11-15.

[16] A. Da Silva, M. Barbosa. Facebook Groups : the use of social network in the education. International Symposium on Computers in Education (SIIE). 2015: 185-188.

[17] E. Dogoriti, J. Pange. The use of social networking and learning management systems in English language teaching in higher education. Information and Learning Technologies. 2014, 31 (4): 254-263.

[18] R. Judele, D. Tsovaltzi, T. Puhl, A. Weinberger. Collaborative Learning in Facebook: Adverse Effects of Individual Preparation. 47th Hawaii International Conference on System Science Collaborative. 2014: 1616-1624.

[19] W. Peeters. Metacognitive awareness in foreign language learning through Facebook A case study on peer collaboration. Dutch Journal of Applied Linguistics. 2015, 4 (2): 174-192.

[20] T. Puhl, D. Tsovaltzi, A. Weinberger. A Long-Term View on Learning to Argue in Facebook: The Effects of Group Awareness Tools and Argumentation Scripts. Computer Supported Collaborative Learning Conference (CSCL), Gothenburg, Sweden. 2015: 16-26.

[21] Ö, Özyurt, H. Özyurt. Using Facebook to enhance learning experiences of students in computer programming at Introduction to Programming and Algorithm course. Computer Applications in Engineering Education. 2016, 24(4): 546-554.

[22] B. Watson, M. Cooke, R. Walker. Using Facebook to enhance commencing student confidence in clinical skill development: A phenomenological hermeneutic study. Nurse education today. 2016, 36: 64-69.

[23] F. Fernández-Peña, P. Urrutia-Urrutia. Construcción de un repositorio digital académico utilizando facebook. Tecnología, innovación e investigación en los procesos de enseñanza-aprendizaje. Edit. Octaedro. 2016: $2427-$ 2435. 